\title{
Decolonizing Social Capital: Historically Engaging Social Capital as a Determinant of Public Health
}

Ali Malik

\begin{abstract}
Since the advent of Robert Putnam's seminal piece "Bowling Alone," the notion of social capital as a strategy and indicator for development has gained significant traction. The notion is being used as a determinant for public health, meaning strong, positive relations within one's communal networks are good for aggregate public health. In this paper, I will build on the critique of social capital as applied to public health, as set forth by Muntaner, Lynch, and Smith. This critique finds currency in its suggestion of social capital as a shift away from a materialist explanation of structural inequality which foregrounds race, class, gender, sexual orientation, and their potential intersectionalities. In essence, as the authors explain, this shift towards a social capital focus in public health can potentially lead to "community blaming," which embodies a form of cultural determinism. Muntaner, Lynch, and Smith's critique is formidable and my intention is to augment it with a historical layer. I will draw a historical comparison between the underlying logics and cultural implications of employing social capital as a determinant of public health with its colonial counterpart. My purpose is not necessarily to indict social capital, when used as a determinant of public health, as explicitly a neocolonial practice. Rather, I argue that there are similar, if not uncomfortable, logics at play that drive both the contemporary and colonial examples.
\end{abstract}

Keywords: Public health indicators; social capital; postcolonial approaches to health 
Since the advent of Robert Putnam's seminal piece "Bowling Alone," the notion of social capital as a strategy and indicator for development has gained significant traction. Putnam (1995), while working within the context of building capacity for civil society, defined social capital as " "features of social organization such as networks, norms, and social trust that facilitate coordination and cooperation for mutual benefit"” (p. 67). Recently, social capital has been expanded and applied to the public health arena. The notion is being used as a determinant for public health, meaning strong, positive relations within one's communal networks are good for aggregate public health (Baum 1997). In this paper, I will build on the critique of social capital as applied to public health, as set forth by C. Muntaner, J. Lynch, and G.D. Smith (2000) in their piece "Social Capital and the Third Way in Public Health." This critique finds currency in its suggestion of social capital as a shift away from a materialist explanation of structural inequality which foregrounds race, class, gender, sexual orientation, and their potential intersectionalities. In essence, as the authors explain, this shift towards a social capital focus in public health can potentially lead to "community blaming," which embodies a form of cultural determinism, as will be elaborated upon later in the paper.

Muntaner, Lynch, and Smith's critique is formidable and my intention is to augment it with a historical layer. I will draw an historical comparison between the underlying logics and cultural implications of employing social capital as a determinant of public health with colonial conceptions of determinants of public health. Colonial historian Megan Vaughan (1991), commenting on colonial biomedical discourse, states that " $(\mathrm{t})$ he underlying assumption of this discourse was that disease was produced by the disintegration and degeneration of 'tribal'cultures, which was seen to be occurring in the process of individualization and modernization. This was a cultural rather than a materialist model, the argument being that 
Africans were made sick not by the material changes to their lives, but by their cultural "maladaptation" to modern life" (p.230).

My purpose is not necessarily to indict social capital, when used as a determinant of public health, as explicitly a neocolonial practice. Rather, I seek to highlight that there are similar, if not uncomfortable, logics at play that drive both the contemporary and colonial examples. Both diverge from a materialist analysis of disease and disease prevention towards a model that places the onus almost squarely on communities for their aggregate health outcomes, while neglecting to critically engage with the production of systemic inequality and poverty by international and domestic institutions and decision-makers. Uncritically deploying social capital as a determinant for public health thus can result in victim/community blaming for poor aggregate health, ultimately substantiating neoliberal individualization and perpetuating social stigmatization of already marginalized groups. Moreover, and possibly more distressing, is that it actually provides a shield against uncovering Northern/Western complicity in the creation, spread, and maintenance of poor public health trends (Pogge, 2005). In addition to producing a “forward-looking analysis," (CSDH, 2008, p.104) as the World Health Organization calls for in regard to social determinants of public health $(\mathrm{CSDH}, 2008)$, I suggest that perhaps we incorporate a historical analysis when assessing social capital as a determinant of public health.

To begin with, it is necessary to trace the origins of social capital in order to better understand how the notion has been applied as a determinant of public health. An array of scholars have put forth conceptions of social capital; Pierre Bourdieu and Robert Putnam provided two prominent yet divergent notions of social capital. While Putnam focuses on networks, norms, and social values, Bourdieu places these concepts into a wider analysis of economic and cultural capital, although his skepticism about altruistic action contrasts with 
Putnam's emphasis on trust. Bourdieu's critical conception of social capital is centered on materiality, power relations, domination, and social conflict, in contrast to Putnam's emphasis on functionalism, collective values, and social integration (Siisiäinen, 2000).Siisiäinen (2000) notes

the choice between Putnam and Bourdieu depends; first, on what problems we are interested in and, second, on our position concerning the dispute between the sociology of integration and the sociology of conflict. Trust and voluntary associations create consensus and economic welfare in Putnam's approach on the condition that the specific interests of certain groups and conflicts between them are cancelled out. Bourdieu's sociological focus is on the conflictual fields, including the inside working of voluntary associations, and on the structures of power and violence that are produced and reproduced/destroyed by agents who have an interest in the game that is played in the field in question. (p.23)

Employing Bourdieu or Putnam's theoretical lens is a choice not only about how one intends to approach a given social problem but also to what extent one's political conflicts over inequality will be emphasized in their analysis. While Bourdieu's conception might well formulate eventual radical collective action, Putnam's seems to invite togetherness and cohesion for purposes of market discipline and economic rationality. Commenting on social capital and community development, Mayer and Rankin state that while 'disadvantaged' community-based organizations in the Global North are "encouraged to activate local self-organization and participate in new governance strategies along with market and state representatives, find themselves restricted to certain forms of local capacity-building" (Mayer \& Rankin, 2002, p.807). They further add that "The design of the programs and governance networks within which they now function makes it their task to identify and mobilize the resources within "neighborhood problems" - not to analyze or resist the structural causes of new forms of exclusion" (Mayer \& Rankin, 2002, p.807). 
My critique is focused on Putnam's theory of social capital, as it is the primary framing for social capital as a determinant of public health. The World Bank has been a strong advocate of social capital usage, and states the following in regard to health, nutrition, and population:

Smoking, sanitation, and sexual practices are behaviors which impact public health and are deeply entwined with culture and norms. Social norms and networks can promote healthy or unhealthy practices. Social capital and education can help people to make informed decisions about how their behavior impacts their health while providing social support for making healthy (or in many cases, unhealthy) decisions.

Shared values and norms can have an impact on the level of community violence and, therefore, on health.(World Bank, Social Capital Can Improve Health Through Enforcing or Changing Societal Norms, Sec. 5)

David Slater (2008) notes that the World Bank is following Putnam's social capital approach, featuring trust, norms, and networks that might increase societal efficiency (p.108). Moreover, a Health Canada policy paper on social capital and public health emphasizes Putnam and James Coleman's contributions to social capital, built around generalized levels of social trust, without a single mention of Bourdieu's social capital theory (van Kemenade, 2002). This indicates a level of institutional backing for Putnam's theory of social capital, although Bourdieu's social capital can be seen in Carpiano's health-based research (2006), as well as Takahashi and Magalong's (2012) recent theory of 'disruptive' social capital in HIV/AIDS community-based research. However, Macinko and Starfield's (2001) review of social capital literature in regard to health reveals that "social-capital measures used in the health literature are not consistently based on any one theoretical tradition (p.411).

Putnam initially put social capital at the forefront of Political Science scholarship. In "Bowling Alone," Putnam (1995) explores the deteriorating nature of American communal relationships, particularly within the context of civic engagement. Putnam states that social capital "refers to features of social organization such as networks, norms, and social trust that 
facilitate coordination and cooperation for mutual benefit," (p. 67) while describing some of the perceived benefits of a social capital base:

Such networks facilitate coordination and communication, amplify reputations, and thus allow dilemmas of collective action to be resolved. When economic and political negotiation is embedded in dense networks of social interaction, incentives for opportunism are reduced. At the same time, networks of civic engagement embody past success at collaboration, which can serve as a cultural template for future collaboration. Finally, dense networks of interaction probably broaden the participants' sense of self, developing the "I" into the "we," or (in the language of rational-choice theorists) enhancing the participants' "taste" for collective benefits. (p. 67)

In essence, social capital is the sum of relationships, attitudes, and fluid networks within a community. In regard to public health, researchers have measured social capital in terms of the social, economic, and cultural resources available to a family, neighborhood, or community. It can be a means to link diverse members of a community with something as simple as professional or recreational clubs, neighborhood associations, political or social groups. It also combines who we see and interact with on a daily basis, whether at school or work, or at a social or a religious gathering. While I have provided a limited set of examples, the point is to convey how complex and varied these relations exist within and interact with each other at intersectional micro, everyday levels.

Moreover, social capital has begun being applied to public health, in particular as a measurable determinant of public health. At its very core, using a social capital lens to analyze trends in public health appears to be fairly intuitive; communities and societies with strong, positive social capital are more likely to produce positive health outcomes, while those lacking social capital or operating with negative social capital are more likely to produce negative health outcomes. For example, if individuals are a member of a community that has strong high school graduation rates, active religious participation, and robust civic engagement, then based on their 
social capital, we might assume those individuals are likely to have good health and access to health resources. One could flip the above scenarios in order to assume greater chances of poor health and a lack of access to health resources. While in reality there are several other communal factors at play that I have not accounted for, the example above demonstrates how social scientists could be prone to uncritically employ social capital as a determinant of public health. It contains an almost common-sense logic within it, which gives one an impetus to unpack the concept and critically engage with it.

Muntaner, Lynch, and Smith (2005) initiated a neo-materialist critique of social capital in their piece "Social Capital and the Third Way in Public Health." Elaborating on the "commonsense" attribute seemingly inherent in linking social capital and public health, they comment that “(i)nfectious disease transmission depends on who is connected to whom, and it is possible that other disease processes are also influenced by the pattern of connections within a population," (p. 110) while also warning that "overly simplistic interpretations of the patterns of connections among people may mask, not reveal determinants of population health" (p. 110). This position is in contrast with Richard Wilkinson's 'psycho-social' position (1996), arguing that social capital concerns were significant to the extent that they were part of the psycho-social effects of rapidly increasing socioeconomic inequality within affluent societies. The psycho-social approach diverges from the traditional 'social support' view, which advocates that any kind of social capital is good for one's individual health. Wilkinson's research emphasizes the importance of communal social support mechanisms within poor communities located in affluent countries. In this view, psycho-social causes of poor health outweigh material inequalities because the most basic levels of subsistence are met even for the poorest communities in these countries. Thus, these psycho-social causes can be addressed by and within communities with greater individual 
involvement and social support or 'self-help' networks. This coincides with neoliberal objectives in cutting state expenditures in public services, decentralizing state policy in favor of micro-level communal projects which might serve as a buffer to market-generated inequalities (Harriss, 2001), and advocating for individuals and their aggregate communities to take responsibility for their levels of social support and ensuing public health outcomes.

Szreter and Woolcock (2004) attempted to reconcile the neo-materialist and psychosocial positions, as well as the original 'social support' view, by further developing a theoretical basis for social capital in regard to public health. Their analytical framework distinguishes between bonding, bridging, and linking forms of social capital. Bonding refers to the relations between individuals who view themselves as having similar social identities, while bridging denotes trust and respect-relations between people who know they are not alike in some social sense (pp. 654-55). Szreter and Woolcock (2004) define 'linking' social capital "as norms of respect and networks of trusting relationships between people who are interacting across explicit, formal or institutionalized power or authority gradients in society" (p.655). They further comment that 'linking' social capital, "especially in poor communities, it is the nature and extent (or lack thereof) of respectful and trusting ties to representatives of formal institutions-e.g. bankers, law enforcement officers, social workers, health care providers - that has a major bearing on their welfare" (p.655).

Notably, Szreter and Woolcock (2004) emphasize ‘linking' social capital's importance without accounting for the political, economic, and historical factors that shape the volume of positive or negative 'linking' social capital found within a given community. 'Linking' social capital, which Szreter and Woolcock (2004) propose will address for bonding/bridging theories of social capital lack of recognition of power relations, continues to ignore the socio-political 
contexts which have shaped some communities' lack of trust in domestic and/or international institutions. Histories of marginalization based on race, class, gender, and geography provide clues as to why there might be deficiencies in 'linking' communities and institutions; failure to bring these questions into the social capital debate signifies the absence of a political conversation about material inequality. This is akin John Harriss' claim of depoliticization around the use of social capital in international development (Harriss, 2001).

It is from this point from which we might accurately describe what is implicitly at stake here in terms of public health research; the current use of social capital as a determinant of public health is symptomatic of a shift away from engaging with a material-based analysis of public health. Rather than centering material inequality as a determinant for public health, there is a turn in favor of a social psychology approach that might prioritize social, cultural, and/or communal determinants of public health. Muntaner, Lynch, and Smith (2005) remark that "[c]onflating the political, cultural and economic aspects of a community under the one umbrella of social capital, may mask important conceptual distinctions as to the origins of those group resources and may obscure the fact that these dimensions are not necessarily equally important as determinants of health" (p. 109). Keon and Gilbert (2013) analyze social capital and health disparities in African American communities, stating

A history of inequality has left imprints on African-American health, and AfricanAmericans have used the mechanisms of social capital to deal with that inequality. Social capital movements have driven the state of African-American health in the post-slavery era, yet when examining social capital and health race/ethnicity has been left out of the conversation. (p.307)

Instead of interrogating domestic and international institutions and actors that establish the global economic terrain from which inequalities and infectious diseases might emerge, we are at risk of setting our gaze upon communities bound with dense yet fluid, complex networks while 
neglecting the internal and external power relations, historical processes of domination and reification, and intersectionalities of class, race, gender, sexual orientation which interact and morph within those networks.

Analyses of social capital necessitate a thorough understanding of its formation, or how social capital within a particular community or group actually came to be. The notion needs to be dissected and reconstructed with context. The implications of employing social capital as a determinant of public health without initially uncovering the layered political and social context are ominous, as mentioned by Muntaner, Lynch, and Smith (2005); communities may be held solely responsible for their aggregate health outcomes, or "community blaming," thus justifying further privatization of health services. Pearce and Smith (2001) comment that social capital

is flavored with an economic essence in which the consideration of social factors is justified as a means to the end of economic growth (for those with a marketdriven ideology) as well as an end in itself (for those with a more communitarian ideology). Thus, it appears to represent a "third way," in which the community forms the missing link between macrolevel economic policies and individuallevel behaviors. In practice, the term has been widely embraced across the political spectrum by different interest groups who have interpreted it according to their own agendas. In particular, it has been used to depoliticize issues of social and economic development. (p.127)

These implications are significant, as an overreliance on social capital might strengthen the neoliberal narrative of individualized responsibility, although associated with communities, thus ultimately perpetuating a medicalized discourse of the 'other.' Commenting on the link between social capital and privatization of public resources, Chris Scanlon (2003) states:

Perhaps the most serious problem with social capital, however, is the way in which it "instrumentalises" some forms of communal life.

Against the abstract, impersonal relations of both the market and the bureaucracy, the concern with social capital appears to offer a timely reassertion of the importance of intimate social bonds outside the arguments of economic rationalists. 
Social capitalists do focus on such relationships, but they do so in order that they might be more effectively harnessed towards the achievement of specific policy outcomes.

One of the effects of this is that social capitalists tend to subsume the intimate and informal non-economic bonds of community into the cost-benefit calculations of the market.

It is not surprising then that many discussions of the benefits of social capital frequently present increased economic efficiency and savings in health, education and law enforcement as the strongest argument for trusting one another.

If we all trust one another, the argument goes, then the costs of doing business are lessened, public expenditure can be decreased, and so on. (Scanlon, 2003, para.15)

Moreover, David Slater (2004) notes that social capital's policy effect "is more appropriately understood as being complementary to that of central categories of privatization, commodification, competition, and open markets," so that "structural adjustment has been more incisive in its influence" (p.110).

While the notion of individualization might seem awkward as applied to a community, the core logic remains intact; communities, like individuals, are projected into a binary with the so-called free market. Communal relations under Putnam's social capital are subject to market discipline in the form of austerity yet also asked to 'pull themselves up by their bootstraps' in order to escape poverty and social ills. Within this binary, communal histories of colonial displacement, transnational exploitation, and structural adjustments form a background which free market logic silences and disavows. Each community's present and historical circumstances cannot fit into the binary. Aggregate health will be analyzed from the lens of the market, and poor health outcomes will be viewed as failures to successfully integrate and participate within 'rational' market behavior, rather than as possible failures of the economic policies and ideology which emanate from the free market approach itself. 
Communities today, as we see and define them from a public health lens, did not emerge from an equal or objective starting point, but are cloaked in context. They were not constructed, internally or externally, in a vacuum devoid of power relations. Discussing social determinants of health from a First Nations perspective, Reading, Kmetic, \& Gideon (2007) state

policies linked to the political economy of nation-states create strong forces which undermine First Nations peoples' legitimate aspirations for self-determination and impose change necessary to ensure survival ... Consequences felt by First Nations include: widening of the gap in income distribution; economic marginalization; profound vulnerability to economic policies of exclusion whereby their interests are not even recognized both nationally and worldwide. (p.7)

Each community has been developed or underdeveloped within particular histories and geographies; the global North established Core communities while simultaneously producing Peripheral communities wrought with colonial and imperial encounters.

In Curing their Ills: Colonial Power and African Illness, Megan Vaughan (1991) delves into these encounters with a focus on public health and Western biomedical discourse. Vaughan (1991) argues that in British colonial Africa, biomedical disciplines played a crucial role in constructing what is widely perceived as 'African' identity as an object of knowledge, and expounded classification systems and practices which have been seen as essential to the operation of colonial power. Vaughan (1991) identifies the gradual emergence of the idea of 'culture' as a separate and determining feature of health in colonial medical discourse. Vaughan (1991) claims that the social sciences were indeed integral in the production of colonial biomedical knowledge, stating that "what is striking about so much of the medical knowledge produced in and about colonial Africa is its explicit concern with finding social and cultural 'origins' for disease patterns. Biomedicine drew for its authority both on science and social science" (p.6). Similarly today, social capital in its role as a determinant of public health, is a 
creation of the social sciences focused on locating public health trends within established social and cultural networks. Vaughan (1991) further adds

Medical discourse operated by locating difference and differences in the body, thereby not only pathologizing them but also naturalizing them. As the notion of biological 'race' came under attack, white liberals (amongst whom were many doctors), became uneasy with medical theories which relied on the embodiment of difference, and elaborated other theories to account for perceived variations in, for instance, the manifestation of a disease amongst different social groups. In these theories medicine demonstrated its ability to draw on 'social science' as well as on natural science for its authority. (p.13)

Therefore, it can be reasonably established that the social sciences have long contributed to biomedical theories and discourse in producing explanations for public health outcomes. They contributed to the explanatory shifting from explicitly racial 'origins' for disease and poor health to cultural and social 'origins.' Interestingly, what seems to be missing from these analyses is a distinctly material account, as Vaughan (1991) adds "[t]he differential incidence of many diseases was attributed not to the material consequences of industrialization and urbanization but to 'maladaptation' on the part of Africans" (p.12). While searching for something resembling a natural account of disease in Africa, the seismic material changes produced as a result of colonial capitalism were conveniently overlooked. Rather, the shift towards cultural difference as a determinant of colonial health was beneficial in virtually ignoring the role of colonial industrialization in the production and spread of disease, thereby in a sense concealing, reifying and naturalizing the colonial experience. Africans were seen as particularly vulnerable to certain diseases on account of their cultural practices, tending towards the designation of blame. In summation, analyzing colonial public health and disease trends was rarely done so through a material approach, but blamed on the colonized populations for their perceived 'inferior' cultural practices, as Vaughan (1991) adds 
[s] usceptibility to disease in Africans, then, was defined not through an analysis of the conditions under which they lived and worked, or through notions of individual lifestyle and responsibility (though missionary medicine stressed exactly this), but rather through the idea that the cultural practices of different ethnic groups disposed them to various disease patterns. (p.46)

Vaughan brings to light the ascription of cultural determinism to colonial medical discourse.

While the emphasis on cultural determinism for African health was a shift from an earlier colonial reliance on biological determinism, it missed almost entirely and non-coincidentally, the material changes to conditions of everyday life for the colonized. These conditions were largely impacted by external events; colonial conquest, the imposition of capitalism and its impending urbanization and displacement for the transfer of resources, and the introduction of new diseases previously alien to the continent. Vaughan (1991) comments "[i]n the case of the history of tuberculosis in South Africa for example, the complex interactive process between the political economy of mining labour and the medical construction of tuberculosis is very evident," (p.7) adding that "the shape which the medical constructions on the disease took in South Africa can only be interpreted by reference to the fact of sickness and debility amongst black miners, and the problem this posed for employers of black labour" (p.7).

Rita Headrick (1994)further provides an example of working conditions revolving around the construction of the French-led Congo-Ocean Railway (CFCO) in 1921, stating that " $(\mathrm{t}) \mathrm{he}$ worst conditions were for the people digging the two-kilometer tunnel of Bamba, a massive project which allowed the route to be shortened considerably. The men were continually breathing dusty air and being dripped on from the roof of the tunnel. Most coughed constantly" (p.296). Respiratory infections, amoebic dysentery, hookworm, and malaria were disproportionally the causes of mortality among CFCO workers, as Headrick (1994) adds

The building of the railroad was a tragedy for the people of French Equatorial Africa. Thousands of injured and chronically sick workers returned home to 
become burdens on their communities. Disabled workers received no rehabilitative care or pensions, but only a minimal one-time payment. The loss of life was tremendous: about 20,000 deaths. (p.30)

Thus, one can begin to hypothesize the vital role capital-induced industrialization and urbanization played in determining public health in colonial Africa. Western biomedicine, as driven by health professionals and its accompanying discourse, was more eager to examine what was occurring within African communities and label those practices as 'inferior' and unable to adapt to a vision of modernity which presupposed technological and medicinal advancement, monotheistic piety, and the establishment of and participation in market-based economic and legal structures. In the view of the colonizer, the colonized themselves were determined to be the cause of poor health and disease outbreak, for it was their 'primitive' practices which doomed them to death and disease. Echoing medical sociologist Caroline Allen (1998), Reading, et al. (2007), affirm that "[t]he Western biomedical model, premised on European cultural constructs, does examine some determinants of health - such as housing, employment and education - but is unable to absorb the negative health impact of colonialism and is culturally limited in its definition of wellness" (p.21). Social capital as a determinant of public health runs a somewhat similar risk in its current uncritical use; certain communities will be deemed guilty of harmful practices, which might be uncritically portrayed as inherent within those communities without digging deeper into the structural material roots of those practices themselves. For instance, while it has been established that sex workers are at high-risk of contracting and facilitating the spread of HIV (WHO, 2013), far less consideration has gone into contextualizing this trend within globalized economic networks, the increased mobility of transnational capital, and laborinduced migratory patterns of the rural poor. A critical approach might ask not only what are the conditions that drive individuals to resort to sex work, to which one might point towards poverty and socioeconomic need as the obvious answer, but also how confluence of global poverty, 
patriarchal communal structures, and the global opening of local spaces facilitate both the production and consumption of sex work and the spread of HIV.

What characterized the colonial approach to public health, as now seems to be the case with social capital, is the notable absence of a foregrounded material analysis. However, introducing a political economy of social capital can be fruitful only if it is a critical one, with far-reaching breadth and scope; disparities in communal public health aggregates cannot be viewed as 'natural' or inevitable but rather as fluid historical processes that are neither unprompted nor anonymous. Social capital, if it is to be critically employed as a determinant of public health, has to at least be willing and capable of unpacking the root causes of public health trends within communities. Instead of looking at what is happening within particular communities then using those observations to make claims as to what is causing poor health trends, social scientists must take the next step and engage with the root causes that influence what is taking place within a community, as well as why and how. As stated earlier, communities were not constructed and contemporarily maintained in a vacuum devoid of power, history, economics, and day-to-day circumstances. This point is reaffirmed by Reading, et al. (2007) comment on First Nations communities:

A vision for improving health involves partnership among First Nations communities to investigate the spectrum of local and world health issues that move beyond geo-political boundaries to involve governments, NGOs and the special interests of First Nations peoples, many of whom live in extreme poverty due to the historic and present day socio-economic forces of colonization and globalization. Such a vision must go beyond epidemiological description of public health outcomes to a view that celebrates their unique economic, political and social factors, ultimately providing solutions to the pressing need for First Nations peoples to achieve a level of health and well-being that is free from discrimination. (p.7)

The consequence of viewing these disparities as natural or inevitable is that we begin to internalize them as health and development problems to be accommodated, not defied. We, 
Northern scholars, health professionals, and activists, knowingly or unknowingly naturalize the very health problems to which we tend. Negative and pervasive trends in public health, particularly in, but by no means exclusive to, the Global South, do not only affect the sick, or 'patients' so to speak, but the 'healthy,' as well. Thus, avenues must be opened for greater scrutiny among the relationship between international financial institutions, structural adjustment programs, and poor health and disease trends (Manfredi, 1999), globalization and its consequential rural-to-urban migration effects in the production of urban slums and poor health (Davis, 2007), as well as race-to-the-bottom economic 'development' and its proliferation of inhumane working conditions for much of the global labor force. While this is not meant to be an exhaustive list, it aims to set a kind of baseline for some of the kinds of relationships a critical political economy of social capital might seek to interrogate.

Throughout the course of this paper I have attempted to build on Muntaner, Lynch, and Smith's (2005) critique of social capital by adding to it a historical element analysis. As stated previously, the intention of this paper was not to squarely equate social capital as a neocolonial determinant of public health, nor was it a call to abandon social capital theory all together within the field of public health. Alternatively, my intention is to call for a more substantial engagement with social capital, one that might employ a critical political economy component while accounting for historical processes and asymmetrical power relations. Further, the purpose was to illustrate the similarities and insidiousness of the logics that underpin both social capital and colonial biomedical discourse and practice, so that we as social scientists might more acutely tread the troublesome slippery slope that social capital as applied to public health may bring. This slope might lead to 'community-blaming', evoking a return to cultural determinism. While this undoubtedly furthers the social stigmatization of already marginalized communities and 
social groups, it also works to absolve Northern actors, both institutional and individual, of their own complicity in the creation, maintenance, and spread of poor health outcomes and their facilitative conditions. Our focus is set on the victims of poor public health; a shift towards an approach that foregrounds both the producers and beneficiaries of poor public health could prove to be a fruitful one. 


\section{References}

Allen, C. (1998). Health promotion, fitness and bodies in a postcolonial context: The case of Trinidad. Critical Public Health, 8(1), 73-92. Retrieved August 4, 2014, from http://www.tandfonline.com/doi/abs/10.1080/09581599808409213?journalCode=ceph20 \#.U-f1YPldWSo.

Baum, F. (1997).Public health and civil society: Understanding and valuing the connection. Australian Journal of Public Health, 21, 673-675.

Carpiano, R. (2006). Toward a neighborhood resource-based theory of social capital for health: Can Bourdieu and sociology help? Social Science \& Medicine, 62(1), 165-175. Retrieved August 1, 2014, from http://www.ncbi.nlm.nih.gov/pubmed/15992978.

Davis, M. (2007).Planet of Slums (Verso) (Republished 2007).

Gilbert, K., \& Dean, L. (2013). Social Capital, Social Policy, and Health Disparities: A Legacy of Political Advocacy in African-American Communities. In Global Perspectives on Social Capital and Health (pp. 307-323). Springer.

Headrick, R. (1994).Colonialism, Health and Illness in French Equatorial Africa, 1885-1935 (African Studies Association Press).

Health 2020: Policy framework and strategy. (2012, August 1). Retrieved August 7, 2014, from http://www.euro.who.int/__data/assets/pdf_file/0020/170093/RC62wd08-Eng.pdf?ua=1.

Macinko, J., \& Starfield, B. (2001). The Utility of Social Capital in Research on Health Determinants. The Milbank Quarterly, 79(3), 387-427. Retrieved August 6, 2014, from http://www.ncbi.nlm.nih.gov/pmc/articles/PMC2751199/.

Manfredi, C. (1999).Can the resurgence of malaria be partially attributed to structural adjustment programmes?Parassitologia, 389-90. 
Mayer, M., \& Rankin, K. (2002). Social Capital and (Community) Development: A North/South Perspective. Antipode, 34(4), 804-808. Retrieved August 5, 2014, from http://onlinelibrary.wiley.com/doi/10.1111/1467-8330.00273/abstract.

Muntaner, C., Lynch, J., \&Smith, GD. (2000).Social capital and the third way in public health. Critical Public Health, 10, 107-124.

Pearce, N., \& Davey Smith, G. (2003). Is Social Capital The Key To Inequalities In Health? American Journal of Public Health,93(1), 122-129. Retrieved August 3, 2014, from http://www.ncbi.nlm.nih.gov/pmc/articles/PMC1447706/.

Pogge, T. (2005).Recognized and violated by international law: The human rights of the global poor.Leiden Journal of International Law, 18, 717.

Putnam, R. (1995).Bowling alone: America's declining social capital. Journal of Democracy, 6, $65-78$.

Reading, J., Kmetic, A., \& Gideon, V. (2007). First Nations Wholistic Policy and Planning Model: Discussion paper for the World Health Organization Commission on Social Determinants of Health Ottawa: Assembly of First Nations.

Scanlon, C. (2003, July 19). The problems with 'social capital' The Age. Retrieved August 8, 2014, from http://www.theage.com.au/articles/2003/07/18/1058035195873.html.

Siisiäinen, M. (2008, July 5-8). Two Concepts of Social Capital: Bourdieu vs. Putnam. Retrieved August 2, 2014, from http://dlc.dlib.indiana.edu/dlc/bitstream/handle/10535/7661/siisiainen.pdf.

Slater, D. (2004). The Rise of Neo-Liberalism and the Expansion of Western Power. In Geopolitics and the post-colonial: Rethinking North-South relations. Malden, Mass.: Blackwell Pub. 
Social Capital and Health, Nutrition and Population. (n.d.). Retrieved August 1, 2014, from http://go.worldbank.org/5DODHABMT0.

Szreter, S. \& Woolcock, M. (2004). Health by association? Social capital, social theory, and the political economy of public health. International Journal of Epidemiology, 33, 650-667.

Takahashi, L., \& Magalong, M. (2012). Disruptive Social Capital in Los Angeles: (Un)Healthy Socio-Spatial Interactions among Filipino Men Living with HIV/AIDS. In Urban Social Capital: Civil Society and City Life (pp. 241-265). Ashgate.

Van Kemenade, S. (2002, July 1). Social Capital as a Health Determinant: How is it Defined? Retrieved August 3, 2014.

Vaughan, M. (1991).Curing Their Ills: Colonial Power and African Illness (Stanford University Press).

Wilkinson, RG. (1996). Unhealthy Societies: The Afflictions of Inequality. London: Routledge.

World Health Organization. (2013). HIV due to female sex work: Regional and global estimates. Retrieved from http://www.who.int/hiv/pub/surveillance/f_sexwork_estimates/en/index.html. 